\title{
Testicular cancer in Geneva, Switzerland, 1970-2012: incidence trends, survival and risk of second cancer
}

\author{
Robin Schaffar, Samaksha Pant, Christine Bouchardy, Hyma Schubert and Elisabetta Rapiti
}

\begin{abstract}
Background: This paper describes the testicular cancer trends for incidence, survival, socio-economic status (SES) disparities and second cancer occurrence in Geneva, Switzerland, a high-risk population.

Methods: We included all testicular germ-cell tumors recorded in the population-based Geneva cancer registry during the period 1970-2012. Changes in incidence trends were assessed using Joinpoint regression to calculate the annual percentage change (APC). Overall and cancer-specific survivals (OS, CSS) were estimated by Kaplan Meyer methods. To evaluate the risk of a second cancer we calculated the Standardized Incidence Ratios (SIR) using the Geneva population incidence rates.

Results: The average annual testicular cancer rate was 7.32/100 000 men, with a non-significant increasing trend during the study period. The highest rates were observed among men younger than 39 years. Despite a trend toward earlier diagnosis, 14\% of patients were diagnosed at a late stage. Patients with non-seminoma tumours and patients with low SES were more often diagnosed with an advanced stage. Both OS and CSS improved during the study period but with strong differences by age, stage, morphology and SES. The risk for developing a second cancer was more than doubled. This risk was particularly high for a contralateral testicular cancer, bladder cancer and pancreatic cancer.

Conclusions: Overall, there was no substantial increase in the incidence of testicular cancer in Geneva in recent decades, however the prognosis has improved. The high risk of developing a second cancer, the differences in stage at diagnosis and survival by SES, require enhanced awareness and surveillance by clinicians, patients and men in general.
\end{abstract}

Keywords: Testicular cancer, Second cancer, Trends, Incidence, Survival, Socio-economic status

\section{Background}

Testicular cancer is a rare cancer, with an annual incidence rate of 1.5 cases $/ 100^{\prime} 000$ men (world adjusted). In Western Caucasian populations in recent decades, there has been a sharp increase of the rate of this disease, and in Norway and Switzerland the rate went up to 12/100' 000 [1]. The disease is more frequent in young men, aged less than 49 years. Hence, in 2012 in Switzerland the rate among men aged 15-39 years reached 20.9/100' 000, representing the most prevalent cancer diagnosed in this age group [1].

\footnotetext{
* Correspondence: Elisabetta.Rapiti@unige.ch Geneva Cancer Registry, Global Health Institute, University of Geneva, Geneva, Switzerland
}



(c) The Author(s). 2019 Open Access This article is distributed under the terms of the Creative Commons Attribution 4.0 International License (http://creativecommons.org/licenses/by/4.0/), which permits unrestricted use, distribution, and reproduction in any medium, provided you give appropriate credit to the original author(s) and the source, provide a link to the Creative Commons license, and indicate if changes were made. The Creative Commons Public Domain Dedication waiver (http://creativecommons.org/publicdomain/zero/1.0/) applies to the data made available in this article, unless otherwise stated. increase in the burden of the disease, also due to an important decrease in mortality rates following the advent of cisplatin-based chemotherapy [1, 2].

The disease has important physiological and psychological impacts on affected men and their families. Given their young age, issues of concern include not only recovery but also the consequences of both the disease and the treatment on sexuality and reproductive capacity.

There is a paucity of data regarding testicular cancer in Switzerland. The latest report from the Canton of Vaud showed one of the highest incidence rates in the world for the years 1974-1999, but with no clear upward trend since early 1990s [3-5]. 
The aim of this study is to provide an overall picture of testicular cancer in the high-risk canton of Geneva by studying the evolution for over 40 years of its incidence, prognosis, and occurrence of second cancers using population- based registry data.

\section{Methods}

\section{Patients and data}

We used data from the population-based Geneva Cancer Registry, which records information on all incident cases of malignant neoplasms occurring in the population of the canton (approximately 490'000 inhabitants) since 1970. Information collected by the registry includes patient's sociodemographic data, tumor data, in particular on the method of detection, histology, stage, treatment in the first 6 months after diagnosis, survival, and occurrence of second tumours. Data are systematically abstracted from hospital and laboratory records by trained tumour registrars. To collect missing clinical and therapeutic data, special questionnaires are sent out regularly to the private practitioners. Death certificates are consulted systematically.

From this database, we identified 624 men resident in the canton of Geneva who were diagnosed with a primary invasive testicular cancer between 1970 and 2012. Cases with non-germinal testicular cancer (24 lymphomas, two Sertoli cell carcinomas, seven Leydig cell tumors, and one leiomyosarcoma) were excluded.

Sociodemographic variables of interest for the study were age ( $\leq 29$ years, 30-39 years, $40-49$ year, $50+$ years), place of birth (Switzerland, Europe, Other), socioeconomic status (SES) categorized in three levels based on the patient's last occupation (low (manual employees, skilled and unskilled workers, including farmers), middle (non-manual employees and administrative staff), and high (professionals, executives, administrators, entrepreneurs)) and period of diagnosis (1970-1979, 1980-1989, 1990-1999, 2000-2012).

We considered the following variables to describe the tumour characteristics: method of detection (symptoms, fortuitous, routine check-up, autopsy or unknown); stage, categorized in four classes based on the pathologic tumor-node-metastasis (TNM) classification or, when absent, the clinical TNM classification; and morphology grouped in two classes: seminoma (International Classification of Diseases in Oncology version 10: 9060-9064 [6]) and non-seminoma (including embryonal carcinoma ICD-O 10: 9070, yolk sac tumor ICD-O 10: 9071, teratoma ICD-O 10: 9080, 9082, 9083, 9102, teratocarcinoma ICD-O 10: 9081, choriocarcinoma ICD-O 10: 9100, 9101, mixed germ-cell tumor ICD-O10: 9085).

The type of treatment received by the patients in the first 6 months after diagnosis was classified as surgery (yes vs. no), radiotherapy (yes vs. no) and chemotherapy (yes vs. no).

\section{Statistical methods}

We calculated the annual incidence rates per $100^{\prime} 000$ men for 11 5-year-periods. We assessed trends in incidence rates using Joinpoint regression [7].

We compared patient, tumour and treatment characteristics by stage using $X^{2}$ (homogeneity and trend tests). Unknown categories were not included in the calculation of the $x^{2}$.

Person-years at risk of developing a second primary cancer (skin non-melanoma excluded) were calculated from the date of testicular cancer diagnosis to the date of the second cancer, date of death, date of departure or 31 December 2013, whichever came first. The expected number of cancer cases was calculated by multiplying the period-age and sex-specific cancer incidence rates of the Geneva population for the period 1970-2012 by the person-years stratified in 5-year intervals. The standardized incidence ratio (SIR) was defined as the ratio between the number of observed cases and the number of expected cases. We calculated SIRs by morphology, stage, treatment and second site of malignancy. A 2tailed 95\% confidence interval (CI) of the SIR was calculated assuming a Poisson distribution of the observed numbers [8].

The patients were followed for vital status from the date of diagnosis to the date of death, the date of departure from the Canton or 31 December 2013, whichever came first. Overall and testicular cancer- specific survival (OS and CSS, respectively) were estimated using the Kaplan Meier method and stratified by age at diagnosis, period of diagnosis, socio-economic status, stage and morphology. Survival differences were tested through log rank test. For the analyses on second primary cancer and survival, one case that was discovered at autopsy has been excluded $(n=589)$. Survival analyses were performed for the whole study period as well as for the most recent years (1990-2012).

\section{Results}

The final cohort comprised 590 patients diagnosed with testicular germ cell tumors between 1970 and 2012. Of these, 340 were diagnosed with seminoma and 250 with non-seminoma.

The incidence rate increased slightly during the period 1970-2012 (APC $=2.85 ; p=0.134$ ) but the trend was not statistically significant (Fig. 1). The trends by age group showed that the most substantial increase was observed in men aged $30-49$ years $(\mathrm{APC}=5.65, p=0.197)$, and the highest incidence rate among patients aged 30-39 years (8.88/100'000) (Fig. 2). 


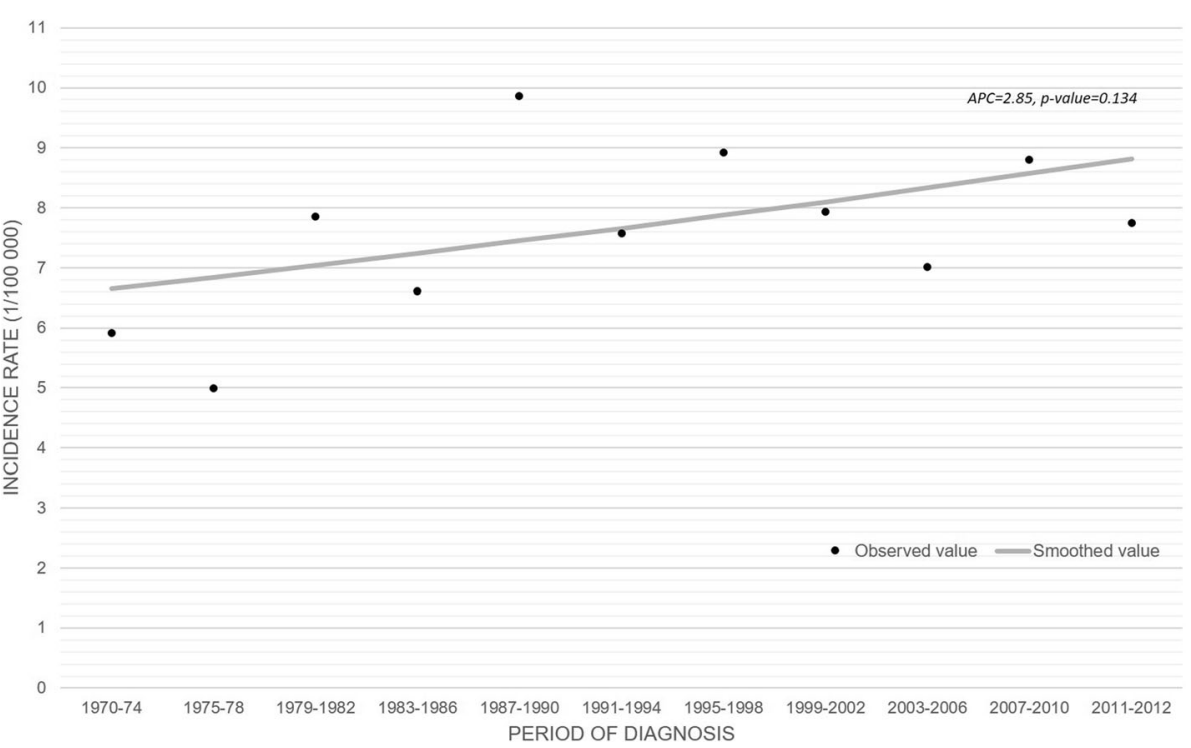

Fig. 1 Observed and smoothed incidence of germinal testicular cancer. 1970-2012

Table 1 shows the distribution of patient, tumor and treatment characteristics according to stage at diagnosis. During the study period, testicular cancer was diagnosed at an earlier stage: in 1970-1979 only 54\% of all cancers were diagnosed at stage I while this proportion reached $72 \%$ in the period 2000-2012 (Chi2 test: $p=0.038$, test for trend: $p$-value $=0.016$ ). Lower SES was found to be associated with later stage at diagnosis: $21 \%$ of low SES men were diagnosed with stage III disease compared with 13 and $9 \%$ of the medium and high SES men, respectively (Chi2 test: $p=0.034$, test for trend: $p$-value $=0.02$ ). Regarding the morphology of the tumour, patients with non-seminoma were diagnosed with more advanced disease compared to seminoma (22, and 7.3\% diagnosed at stage III respectively, $p$-value $<0.001)$. Radiotherapy was administered to 59.7 and $8.4 \%$ of patients with seminomas and non-seminomas, respectively. Chemotherapy was given to 17.4 and $54.4 \%$ of patients with seminomas and non-seminomas, respectively. Patients with an early stage at diagnosis were more likely to receive radiotherapy $(72 \%$ at stage I vs. $5 \%$ at stage III; $p$-value $=0.001)$ and less likely to receive chemotherapy ( $29.7 \%$ at stage I vs. $36.4 \%$ at stage III, $\mathrm{p}=<0.001)$. These results were also significant when the analysis was limited

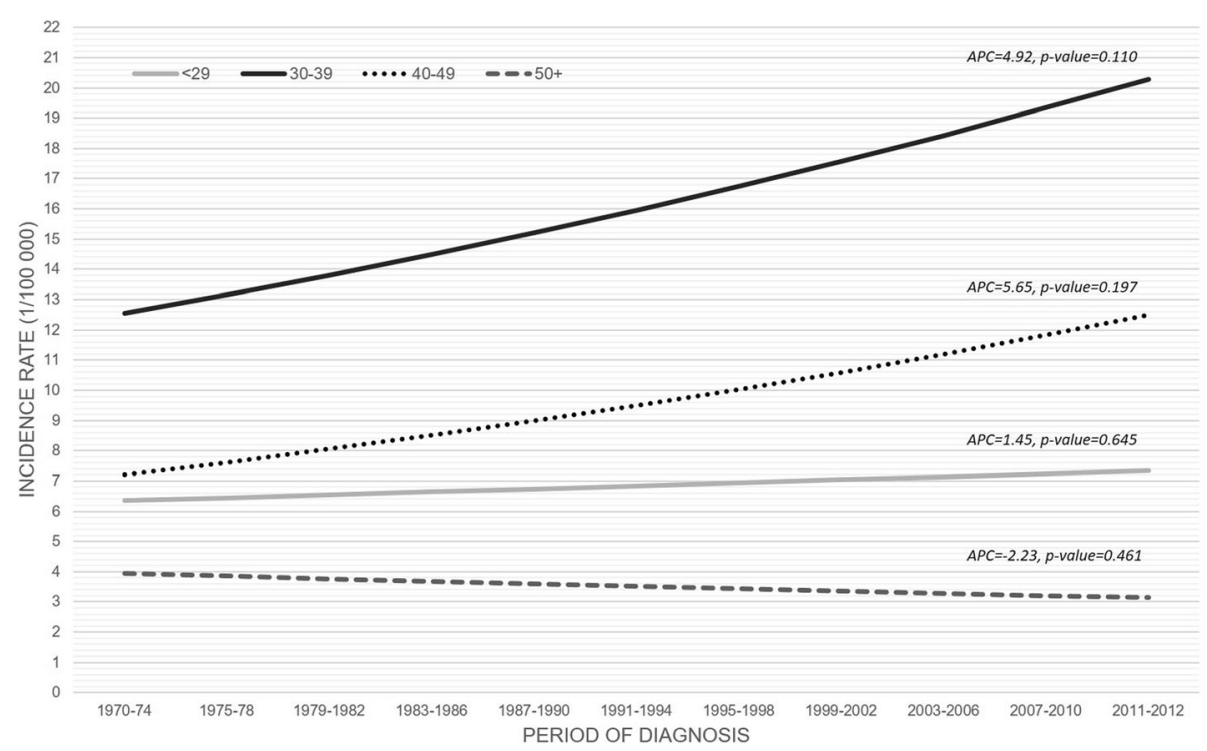

Fig. 2 Observed and smoothed incidence of germinal testicular cancer stratified by age groups. 1970-2012 
Table 1 Socio-demographic, tumor and treatment characteristics according to clinical TNM among 590 men with TGCT. Geneva 1970-2012

\begin{tabular}{|c|c|c|c|c|c|c|c|c|c|c|}
\hline & \multicolumn{2}{|c|}{ Stage I } & \multicolumn{2}{|c|}{ Stage II } & \multicolumn{2}{|c|}{ Stage III } & \multirow{2}{*}{$\begin{array}{l}\text { Unknown } \\
\mathrm{N}\end{array}$} & \multicolumn{2}{|c|}{ Total } & \multirow{2}{*}{$\begin{array}{l}p \text {-value for Chi2 } \\
\text { heterogeneity test }\end{array}$} \\
\hline & $\mathrm{N}$ & $\%$ & $\mathrm{~N}$ & $\%$ & $\mathrm{~N}$ & $\%$ & & $\mathrm{~N}$ & $\%$ & \\
\hline \multicolumn{11}{|l|}{ Period } \\
\hline 1970-1979 & 39 & 54.2 & 21 & 29.2 & 12 & 16.7 & 11 & 83 & 100 & \multirow[t]{4}{*}{0.038} \\
\hline 1980-1989 & 74 & 59.7 & 32 & 25.8 & 18 & 14.5 & 9 & 133 & 100 & \\
\hline 1990-1999 & 105 & 70 & 24 & 16 & 21 & 14 & 9 & 159 & 100 & \\
\hline $2000-2012$ & 153 & 71.8 & 32 & 15 & 28 & 13.2 & 2 & 215 & 100 & \\
\hline \multicolumn{11}{|l|}{ Age group } \\
\hline$\leq 29$ & 116 & 62 & 39 & 20.9 & 32 & 17.1 & 13 & 200 & 100 & \multirow[t]{4}{*}{0.089} \\
\hline 30-39 & 144 & 73.1 & 28 & 14.2 & 25 & 12.7 & 9 & 206 & 100 & \\
\hline $40-49$ & 69 & 65.1 & 27 & 25.5 & 10 & 9.4 & 4 & 110 & 100 & \\
\hline $50+$ & 42 & 60.9 & 15 & 21.7 & 12 & 17.4 & 5 & 74 & 100 & \\
\hline \multicolumn{11}{|l|}{ Place of birth } \\
\hline Switzerland & 289 & 68 & 75 & 17.6 & 61 & 14.4 & 25 & 450 & 100 & \multirow[t]{3}{*}{0.342} \\
\hline Europe & 61 & 59.8 & 26 & 25.5 & 15 & 14.7 & 6 & 108 & 100 & \\
\hline Others & 21 & 65.6 & 8 & 25 & 3 & 9.4 & 0 & 32 & 100 & \\
\hline \multicolumn{11}{|l|}{ Social class } \\
\hline High & 117 & 73.1 & 28 & 17.5 & 15 & 9.4 & 11 & 171 & 100 & \multirow[t]{4}{*}{0.034} \\
\hline Medium & 142 & 67.6 & 40 & 19 & 28 & 13.3 & 11 & 221 & 100 & \\
\hline Low & 81 & 57.4 & 31 & 22 & 29 & 20.6 & 6 & 147 & 100 & \\
\hline Unknown & 31 & 60.7 & 10 & 19.6 & 7 & 13.7 & 3 & 51 & 100 & \\
\hline \multicolumn{11}{|l|}{ Morphology } \\
\hline Seminoma & 245 & 74.5 & 60 & 18.2 & 24 & 7.3 & 11 & 340 & 100 & \multirow[t]{2}{*}{$<0.001$} \\
\hline Non-seminoma & 126 & 50.4 & 49 & 19.9 & 55 & 22 & 20 & 250 & 100 & \\
\hline \multicolumn{11}{|l|}{ Origin of diagnosis } \\
\hline Symptoms & 311 & 65.3 & 92 & 19.3 & 73 & 15.3 & 16 & 492 & 100 & \multirow[t]{5}{*}{0.736} \\
\hline Fortuitous & 31 & 73.8 & 7 & 16.7 & 4 & 9.5 & 1 & 43 & 100 & \\
\hline Check & 8 & 66.7 & 3 & 25 & 1 & 8.3 & 0 & 12 & 100 & \\
\hline Autopsy & & & & & & & 1 & 1 & 100 & \\
\hline Unknown & 21 & 72.4 & 7 & 24.1 & 1 & 3.4 & 13 & 42 & 100 & \\
\hline \multicolumn{11}{|l|}{ Radiotherapy } \\
\hline \multicolumn{11}{|l|}{ Seminoma } \\
\hline No & 94 & 70.7 & 22 & 16.5 & 17 & 12.8 & 4 & 137 & 100 & \multirow[t]{2}{*}{0.007} \\
\hline Yes & 151 & 77.0 & 38 & 19.4 & 7 & 3.6 & 7 & 203 & 100 & \\
\hline \multicolumn{11}{|l|}{ Non-seminoma } \\
\hline No & 122 & 57.6 & 39 & 18.4 & 51 & 24.1 & 17 & 229 & 100 & 0.001 \\
\hline Yes & 4 & 22.2 & 10 & 55.6 & 4 & 22.2 & 3 & 21 & 100 & \\
\hline Chemotherapy & & & & & & & & & & \\
\hline Seminoma & & & & & & & & & & \\
\hline No & 230 & 85.2 & 36 & 13.3 & 4 & 1.5 & 9 & 270 & 100 & $<0.001$ \\
\hline Yes & 15 & 25.4 & 24 & 40.7 & 20 & 33.9 & 2 & 59 & 100 & \\
\hline Non-seminoma & & & & & & & & & & \\
\hline No & 83 & 88.3 & 7 & 7.5 & 4 & 4.3 & 16 & 94 & 100 & $<0.001$ \\
\hline Yes & 43 & 31.6 & 42 & 30.9 & 51 & 37.5 & 4 & 136 & 100 & \\
\hline
\end{tabular}

${ }^{a}$ missing data are not considered for the chi2 test 
to patients diagnosed in the most recent decades (19902013) (data not shown). Seven patients did not undergo surgery for their tumour. No association with stage at diagnosis was found for age and place of birth.

By the end of the study period, 106 deaths had occurred, 48 of which had testicular cancer as the underlying cause. The median follow-up was 10.9 years (range 0.06-42.4 years). Over the entire study period, the 10year overall and cause-specific survival estimates were 88\% (95\% CI: 84-90) and 92\% (95\% CI: 89-94), respectively.

The 10-year survival trend for the whole study period, as well as survival stratified by age, SES, stage and morphology for the most recent years (1990-2012) are presented in Table 2. Both overall and cause specific survival improved significantly from the period 1970-1979 to $2000-2012$ (from 65 to $94 \%$ for overall survival, $p$ value $<0.001$; from 70 to $97 \%$ for cause-specific survival, $p$-value $<0.001)$. As the survival trend appeared to be stable from 1990 onwards, the results of survival by age,
SES, stage and morphology were presented only for the more recent period.

Patients of low SES presented a lower specific survival compared with those from high social class (90, 95\% CI: 79-95, vs. 98, 95\% CI: 91-99) but the difference was not statistically significant $(p$-value $=0.078)$ for the period 1990-2012. It is however worth noting that when considering the whole period (1970-2012), SES was significantly associated with 10-year overall and specific survival SES (data not shown). We found a large difference in survival by stage at diagnosis, particularly for cancer-specific survival wherein men with stage I disease had a 10-year survival of $98 \%$ (95\% CI: 96-100) while for men diagnosed with at stage III it was $81 \%$ (95\% CI: 67-90) ( $p$-value for log rank test<0.001). Survival was higher for seminomas than non-seminomas for both overall and testicular cancer death ( $p$-value for log-rank test<0.001). Regarding morphology subtypes, patients with seminoma presented significantly higher survival rate (10-year overall survival: $96,95 \% \mathrm{CI}$ : 91-98; 10-year

Table 2 10-year overall and cancer-specific survival after a testicular cancer diagnosis. Geneva 1970-2012

\begin{tabular}{|c|c|c|c|c|c|c|}
\hline & \multicolumn{3}{|l|}{ Overall } & \multicolumn{3}{|l|}{ Specific } \\
\hline & $\%$ surviving & $95 \% \mathrm{Cl}$ & Log-rank & $\%$ surviving & $95 \% \mathrm{Cl}$ & Log-rank \\
\hline All patients & $87 \%$ & [84-90] & & $92 \%$ & [89-94] & \\
\hline \multicolumn{7}{|l|}{ By period } \\
\hline 1970-79 & $65 \%$ & {$[54-75]$} & $<0.001$ & $70 \%$ & [59-79] & $<0.001$ \\
\hline 1980-89 & $86 \%$ & [78-91] & & $93 \%$ & {$[86-96]$} & \\
\hline 1990-99 & $94 \%$ & [88-97] & & $96 \%$ & [91-98] & \\
\hline $2000-12$ & $94 \%$ & [87-97] & & $97 \%$ & [93-99] & \\
\hline Patients diagnosed 1990-2012 & $94 \%$ & [90-96] & & $96 \%$ & [93-98] & \\
\hline \multicolumn{7}{|l|}{ By age } \\
\hline$\leq 29$ & $94 \%$ & [86-98] & 0.015 & $96 \%$ & [90-99] & 0.440 \\
\hline $30-39$ & $97 \%$ & [91-99] & & $98 \%$ & [94-100] & \\
\hline $40-49$ & $94 \%$ & [83-98] & & $94 \%$ & [83-98] & \\
\hline $50+$ & $83 \%$ & [61-93] & & $94 \%$ & [79-99] & \\
\hline \multicolumn{7}{|l|}{ By social class } \\
\hline High & $94 \%$ & [85-98] & 0.182 & $98 \%$ & [91-99] & 0.078 \\
\hline Medium & $97 \%$ & [91-99] & & $98 \%$ & [94-100] & \\
\hline Low & $88 \%$ & [77-94] & & $90 \%$ & [79-95] & \\
\hline Unknown & $91 \%$ & [65-98] & & $97 \%$ & [81-1.00] & \\
\hline \multicolumn{7}{|l|}{ By stage } \\
\hline 1 & $96 \%$ & [92-98] & $<0.001$ & $99 \%$ & [96-100] & $<0.001$ \\
\hline$\|$ & $93 \%$ & [74-98] & & $95 \%$ & [72-99] & \\
\hline III & $81 \%$ & [67-90] & & $81 \%$ & [67-90] & \\
\hline Unknown & - & - & & $100 \%$ & - & \\
\hline \multicolumn{7}{|l|}{ By morphology } \\
\hline Seminoma & $96 \%$ & [91-98] & 0.014 & $98 \%$ & [94-100] & $<0.001$ \\
\hline Non-seminoma & $90 \%$ & [83-95] & & $93 \%$ & [87-96] & \\
\hline
\end{tabular}


specific survival: 99, 95\% CI: 94-100) compared to nonseminoma tumours.

Among the 590 patients diagnosed with testicular cancer, 70 had had a second primary malignancy by the end of the follow-up period compared with 34.7 expected (SIR 2.02, 95\% CI: 1.6-2.5, $p$-value $=<0.001$ ) (Table 3). The risk for contralateral cancer of the testis was particularly high (SIR: 20.7, 95\% CI: $11.9-33.7, p$-value $=$ $<0.001)$. The risk for pancreatic and bladder cancers was also increased (SIR 3.76, 95\% CI: 0.8-11, $p$-value $=$ 0.045 and SIR 3.98. 95\% CI: $1.5-8.6$, $p$-value $=0.005$, respectively). The risk of pancreatic cancer was especially high for patients diagnosed with non-seminoma (SIR 9.8, 95\% CI: $1.1-34, \mathrm{p}$ - value $=0.018)$ and for those who had chemotherapy (SIR 13.0, 95\% CI: 1.5-48.1, $p$-value = 0.011 ). The risk of bladder cancer was higher among patients with seminoma (SIR 4.4, 95\% CI: 1.4-10.2, pvalue $=0.006$ ) and those treated with radiotherapy (SIR 5.1, 95\% CI: 1.6-11.8, $p$-value $=0.004)($ data not shown).

\section{Discussion}

This study shows that despite the high and increasing rate of testicular cancer in Switzerland overall, in Geneva the rate did not increase significantly between 1970 and 2012. However, there has been a clear trend towards earlier diagnosis and a significant improvement in survival in Geneva during this period, although differences by morphology and, to a lesser extent, by SES persist. The risk of developing a second cancer, particularly a contralateral testicular cancer, bladder or pancreatic cancer, is very high in these patients compared with the Geneva population.

A majority of Western countries have reported an increase in testicular cancer rates in recent decades $[9,10]$. In Switzerland an increasing trend of testicular cancer has been observed over a period of 35 years with a growth of $1.4 \%$ every 2 years (95\% CI: $0.7-2.0 ; p<0.001$ ). The increasing trend seems to be mainly driven, however, by cantons in the German speaking region which have higher incidence rates than those observed in the French speaking region, to which Geneva belongs [11]. In particular, the rates for the period 2011-2015was 12.1 (95\% CI: 11.512.8) for the German speaking region and 8.9 (95\% CI: 8.2-9.7) for the French speaking region. During the period 1970-2012, we observed only a not statistically significant slightly increasing trend, which was similar to that observed in the French-speaking canton of Vaud [4]. The authors of that study did not find an upward trend in testicular cancer rates during the period 1974-1999; they related their finding to the high testicular cancer rate already reached in the early 1990s [5].

Our results confirm that survival for testicular cancer has improved significantly since the 1970s, with 10 - year cancer-specific survival now reaching 97\%. This improvement can be ascribed to improvements in treatment, particularly with the advent of cisplatin and well defined management recommendations for the disease [12-14]. Survival rates are clearly associated with stage at diagnosis and morphology. In particular, patients in our study who were diagnosed at an advanced stage or with a non-seminoma cancer had a significantly worse survival, consistent with other studies [15].

Results about SES were not statistically significant and must be interpreted with caution. However, this study suggests that men with a low SES experience worse overall and cancer-specific survival in Geneva, despite obligatory health insurance which allows almost uniform access to healthcare and treatments [16]. SES inequalities observed in testicular cancer studies in England and Wales were attributed to differences in stage at diagnosis and access to treatment $[17,18]$. In our study, men of low SES were more often diagnosed with an advanced stage, which could partially explain their lower survival and suggest delay in disease detection. Given the general consensus that routine screening of asymptomatic men, whether with palpation or biomarkers, is ineffective $[12-14,19]$, and that over $80 \%$ of our patients were diagnosed based on symptoms, it is important that both patients and clinicians have a high index of suspicion for this disease to avoid delay in diagnosis [14].

Because of their young age at diagnosis and the improving prognosis, men diagnosed with testicular cancer

Table 3 Standardized Incidence Ratios (SIR) for second primary cancer after a testicular cancer diagnosis according to site. Geneva 1970-2012

\begin{tabular}{|c|c|c|c|c|c|}
\hline Localisation of the second cancer & Observed & Expected & SIR & $95 \% \mathrm{Cl}$ & $p$-value \\
\hline Controlateral testis & 16 & 0.77 & 20.66 & {$[11.9-33.7]$} & $<0.001$ \\
\hline Pancreas & 3 & 0.8 & 3.76 & {$[0.8-11]$} & 0.047 \\
\hline Bladder & 6 & 1.51 & 3.98 & {$[1.5-8.6]$} & 0.005 \\
\hline Prostate & 10 & 7.47 & 1.34 & {$[0.6-2.5]$} & 0.221 \\
\hline Stomach & 2 & 0.93 & 2.15 & {$[0.2-7.8]$} & 0.239 \\
\hline Lung & 6 & 5.4 & 1.2 & {$[0.4-2.4]$} & 0.385 \\
\hline All tumors (skin non-melanoma excluded) & 70 & 34.73 & 2.02 & {$[1.6-2.5]$} & $<0.001$ \\
\hline
\end{tabular}


are at increased risk of developing a second primary cancer during their lifetime. Compared with the Geneva population, our study population showed a doubling of their risk of a second cancer, especially of the contralateral testicular, pancreas or bladder. This is consistent with other reports. The increased risk of second primary cancers has been associated with the use of adjuvant therapies [20,21]. We found an association between the use of radiotherapy and an excess risk of secondary bladder cancer, an infra-diaphragmatic site exposed to the radiotherapy field and between an excess of pancreatic cancer and treatment with chemotherapy, particularly in non-seminoma cancers. These findings align with those of other studies [21-24]. That said, the combined effect of both radiotherapy and chemotherapy on the risk of pancreatic cancer remains unclear. A previous study evaluating the risk of pancreatic cancer after treatment for Hodgkin's lymphoma suggested that patients who had both radiotherapy and $>=6$ cycles of alkylating agents chemotherapy presented the highest risk [25]. Further studies should investigate if the same effect is observed for testicular cancers.

The risk of a second primary cancer for contralateral testicular cancer was extremely high and of the same order of magnitude as seen in other studies [21, 26-29]. Cryptorchidism, environmental exposures, epigenetic aberrations and genetic susceptibility are the suggested etiologic mechanisms for the development of this cancer [30]. The risk factors for a first testicular cancer can predispose for a second such cancer. However, in our study the risk of a second testicular cancer in patients who did not receive adjuvant therapies was the same as the risk for primary testicular cancer in the general population. This supports the theory that chemotherapy is a risk factor for the development of a second testicular cancer, contrasting the results of a study that found a reduced risk after chemotherapy with alkylating agents [31].

One limitation of our study is the relatively small number of cancer cases due to the rarity of testicular cancer and the small size of the population under study. Nevertheless, we included all of the 590 testicular cancer cases that occurred in the Geneva population over a 40year period.

Another potential limitation is the possible lack of completeness of case ascertainment or lack of completeness of follow-up and treatment data. However, the accuracy of the Geneva cancer registry is rather high [32] in general and again as demonstrated in this study by the fact that only 1 case was discovered after death. Furthermore, the median time of follow-up was 11 years, cumulating in 7733 person-years of observation. Another marker of accuracy of the data is that all included cases were morphologically defined. Given the above, the findings are definitively generalizable to the overall patient population of Geneva, while caution should be used when trying to generalize them to other settings.

\section{Conclusions}

In contrast to the overall situation in Switzerland, there has been no significant increase in the incidence of testicular cancer in Geneva since 1970. At the same time, survival rates have been steadily improving. However, given the young age of patients affected, the very high risk of developing a second cancer, and the existence of strong inequalities in terms of stage at diagnosis and survival, heightened awareness of testicular cancer and its risks is vital, among both patients and clinicians, to promote early diagnosis and active surveillance of men diagnosed with this cancer.

\section{Abbreviations \\ APC: Annual Percent Change; Cl: Confidence Interval; CSS: Cause-Specific Survival; ICDO: International Classification of Diseases in Oncology; OS: Overall Survival; SES: Socio Economic Status; SIR: Standardised Incidence Ratio; TNM: Tumor-Node-Metastasis}

\section{Acknowledgements}

The authors thank the staff of the Geneva Cancer Registry for their work and contribution.

\section{Authors' contributions}

ER, SP, CB, RS planned the study. HS collected the data. SP and ER carried out the literature review and prepared the draft of the paper. Data analysis was planned and implemented by RS and SP. ER, CB and RS provided input and feedback on the content data analysis and on the paper drafts. All authors read and approved the final manuscript.

\section{Funding}

The study was supported by the fund Mimosa 2016 of the Faculty of Medicine, Geneva.

\section{Availability of data and materials}

The datasets used and/or analysed during the current study are available from the corresponding author on reasonable request. In compliance with data protection regulations, data are stored at the Geneva Cancer Registry, Geneva, Switzerland.

\section{Ethics approval and consent to participate}

The Geneva Cancer Registry has a general authorization provided by "la commission d'expert du secret professionnel en matière de recherché médicale" (https://www.unige.ch/medecine/rgt/le-rgt/role-du-rgt) to collect nominative data and analyze the anonymized data. Informed consent to participate from patients is therefore unnecessary. Since the study did not require additional clinical information, approval of the Ethics Committee was not required.

\section{Consent for publication}

Not applicable.

\section{Competing interests}

The authors declare that they have no competing interests.

Received: 1 February 2019 Accepted: 2 July 2019

Published online: 10 July 2019

\section{References}

1. Ferlay J, Ervik M, Lam F, Colombet M, Mery L, Piñeros M, Znaor A, Soerjomataram I, Bray F. Global Cancer Observatory: Cancer Today. Lyon: International Agency for Research on Cancer; 2018. Available from: https:// gco.iarc.fr/today 
2. Tandstad T, Kollmannsberger CK, Roth BJ, Jeldres C, Gillessen S, Fizazi K, et al. Practice makes perfect: the rest of the story in testicular Cancer as a model curable neoplasm. J Clin Oncol. 2017 Nov;35(31):3525-8.

3. Levi F, Te VC, La Vecchia C. Testicular cancer trends in the Canton of Vaud Switzerland, 1974-1987. Br J Cancer. 1990 Nov;62(5):871-3.

4. Levi F, Te V-C, Randimbison L, La Vecchia C. Trends in testicular cancer incidence in Vaud, Switzerland. Eur J Cancer Prev. 2003;12(4):347-9.

5. Levi F, Randimbison L, Te VC, Erler G, La Vecchia C. Risk of second cancer after testicular cancer in Vaud and Neuchâtel, Switzerland. Ann Oncol. 1999 Sep;10(9):1129-30.

6. ICD-10. International statistical classification of diseases and related health problems. Geneva: World Health Organization; 2011.

7. Kim HJ, Fay MP, Feuer EJ, Midthune DN. Permutation tests for joinpoint regression with applications to cancer rates. Stat Med. 2000 Feb;19(3):335-51.

8. Breslow NE, Day NE. Statistical methods in cancer research. Bd. 2: the design and analysis of cohort studies. Lyon: International Agency for Research on Cancer; 1987. p. 406. (IARC scientific publications)

9. Znaor A, Lortet-Tieulent J, Jemal A, Bray F. International variations and trends in testicular cancer incidence and mortality. Eur Urol. 2014 Jun;65(6):1095-106.

10. Nigam M, Aschebrook-Kilfoy B, Shikanov S, Eggener S. Increasing incidence of testicular cancer in the United States and Europe between 1992 and 2009. World J Urol. 2015 May;33(5):623-31.

11. Cancer data extracted from the Swiss national dataset managed by the Foundation National Institute for Cancer Epidemiology and Registration (NICER) [Internet]. [cited 2018 Jun 15]. Available from: Available from http:// www.nicer.org/.

12. Souchon R, Hartmann M, Krege S, Lorch A, Mayer F, De Santis M, et al. Interdisciplinary evidence- based recommendations for the follow-up of early stage seminomatous testicular germ cell cancer patients. Strahlenther Onkol. 2011 Mar;187(3):158-66.

13. Albers P, Albrecht W, Algaba F, Bokemeyer C, Cohn-Cedermark G, Fizazi K, et al. Guidelines on testicular Cancer: 2015 update. Eur Urol. 2015 Dec;68(6):1054-68.

14. Krege S, Beyer J, Souchon R, Albers P, Albrecht W, Algaba F, et al. European consensus conference on diagnosis and treatment of germ cell cancer: a report of the second meeting of the European germ cell Cancer consensus group (EGCCCG): part II. Eur Urol. 2008 Mar;53(3):497-513.

15. Sant M, Aareleid T, Artioli ME, Berrino F, Coebergh JW, Colonna M, et al. Ten-year survival and risk of relapse for testicular cancer: a EUROCARE high resolution study. Eur J Cancer. 2007 Feb;43(3):585-92.

16. OECD, WHO. OECD Reviews of Health Systems: Switzerland 2011 [Internet] OECD Publishing; 2011 [cited 2018 Jun 15]. (OECD Reviews of Health Systems). Available from: https://read.oecd-ilibrary.org/social-issuesmigration-health/oecd-reviews-of-health-systems-switzerland-2011_ 9789264120914-en.

17. Nur U, Rachet B, Mitry E, Cooper N, Coleman MP. Survival from testicular cancer in England and Wales up to 2001. Br J Cancer. 2008 Sep 23;99(Suppl 1):S80-2.

18. Woods LM, Rachet B, Coleman MP. Origins of socio-economic inequalities in cancer survival: a review. Ann Oncol. 2006 Jan;17(1):5-19.

19. Shaw J. Diagnosis and treatment of testicular cancer. Am Fam Physician. 2008;77(4):469-74.

20. Maroto P, Anguera G, Martin C. Long-term toxicity of the treatment for germ cell-cancer. A review. Crit Rev Oncol Hematol. 2018 Jan;121:62-7.

21. Travis LB, Fosså SD, Schonfeld SJ, McMaster ML, Lynch CF, Storm H, et al. Second cancers among 40576 testicular Cancer patients: focus on longterm survivors. J Natl Cancer Inst. 2005;97(18):1354-65.

22. Kier MG, Hansen MK, Lauritsen J, Mortensen MS, Bandak M, Agerbaek M, et al. Second malignant neoplasms and cause of death in patients with germ cell Cancer: a Danish Nationwide cohort study. JAMA Oncol. 2016 Dec 1;2(12):1624-7.

23. Fung C, Fossa SD, Milano MT, Oldenburg J, Travis LB. Solid tumors after chemotherapy or surgery for testicular nonseminoma: a population-based study. J Clin Oncol. 2013 Oct 20;31(30):3807-14.

24. Hauptmann M, Børge Johannesen T, Gilbert ES, Stovall M, van Leeuwen FE, Rajaraman $\mathrm{P}$, et al. Increased pancreatic cancer risk following radiotherapy for testicular cancer. Br J Cancer. 2016 Sep;115(7):901-8.

25. Dores GM, Curtis RE, van Leeuwen FE, Stovall M, Hall P, Lynch CF, et al. Pancreatic cancer risk after treatment of Hodgkin lymphoma. Ann Oncol. 2014 Oct;25(10):2073-9.

26. Osterlind A, Berthelsen JG, Abildgaard N, Hansen SO, Hjalgrim H, Johansen B, et al. Risk of bilateral testicular germ cell cancer in Denmark: 1960-1984. J Natl Cancer Inst. 1991 Oct 2;83(19):1391-5.
27. Fosså SD, Chen J, Schonfeld SJ, McGlynn KA, McMaster ML, Gail MH, et al. Risk of contralateral testicular cancer: a population-based study of 29,515 U. S. men. J Natl Cancer Inst. 2005;97(14):1056-66.

28. Andreassen KE, Grotmol T, Cvancarova MS, Johannesen TB, Fosså SD. Risk of metachronous contralateral testicular germ cell tumors: a population-based study of 7,102 Norwegian patients (1953-2007). Int J Cancer. 2011 Dec 15; 129(12):2867-74.

29. Travis LB, Curtis RE, Storm H, Hall P, Holowaty E, Van Leeuwen FE, et al. Risk of second malignant neoplasms among long-term survivors of testicular cancer. J Natl Cancer Inst. 1997;89(19):1429-39.

30. van der Zwan YG, Biermann K, Wolffenbuttel KP, Cools M, Looijenga LHJ. Gonadal maldevelopment as risk factor for germ cell cancer: towards a clinical decision model. Eur Urol. 2015 Apr;67(4):692-701.

31. van Leeuwen FE, Stiggelbout AM, van den Belt-Dusebout AW, Noyon R, Eliel MR, van Kerkhoff EH, et al. Second cancer risk following testicular cancer: a follow-up study of 1,909 patients. J Clin Oncol. 1993;1 1(3):415-24.

32. Forman D, Bray F, Brewster DH, Gombe Mbalawa C, Kohler B, Piñeros M, et al., editors. Cancer incidence in five continents. Lyon: International Agency for Research on Cancer; 2014.

\section{Publisher's Note}

Springer Nature remains neutral with regard to jurisdictional claims in published maps and institutional affiliations.

Ready to submit your research? Choose BMC and benefit from:

- fast, convenient online submission

- thorough peer review by experienced researchers in your field

- rapid publication on acceptance

- support for research data, including large and complex data types

- gold Open Access which fosters wider collaboration and increased citations

- maximum visibility for your research: over $100 \mathrm{M}$ website views per year

At $\mathrm{BMC}$, research is always in progress.

Learn more biomedcentral.com/submissions 